\title{
Revista Enfermería Universitaria ENEO-UNAM
}

\section{Magazine Enfermería Universitaria ENEO-UNAM}

Mtra. Teresa Salazar Gómez

Directora Editoral de la Revista "Enfermería Iniversitaria"

Hace siete años durante la gestión del Lic. Severino Rubio Domínguez se planteo la creación de un medio de difusión de las experiencias, actividades opiniones y productos del quehacer científico de la comunidad de la Escuela Nacional de Enfermería y Obstetricia de la UNAM, este esfuerzo lo integro un grupo de profesores y alumnos dándose a la tarea de planear y diseñar una revista científica que tuviera como objetivo difundir las aportaciones de enfermería en materia de investigación, docencia y práctica profesional, con el propósito de contribuir al fortalecimiento, discusión, e intercambio disciplinar con instituciones académicas, de salud nacionales e internacionales .Así surge la Revista Enfermería Universitaria" como proyecto editorial en el 2004. Su publicación, se ha mantenido en forma ininterrumpida y en mejora permanente gracias al apoyo decidido de la Comunidad Académica, al Consejo Editorial, Comité Editorial y de todos sus integrantes que han apoyado el proyecto a lo largo de estos años, esto nos ha permitido estar abiertos a nuevas propuestas y a un proceso de mejora de la calidad de la revista, por lo que en esta ocasión compartimos con todos nuestros lectores los logros alcanzados en este 2009 ya que nuestra revista a partir de enero del 2010 ingresa al Catalogo de Revistas Científicas y Arbitradas de la UNAM, proyecto creado por el Rector Dr. José Narro Robles a través de la Secretaria General de la UNAM con el propósito de dar difusión y visualización a todas las revistas generadas por nuestra máxima casa de estudios UNAM, distribuyéndose dicho catalogo vía

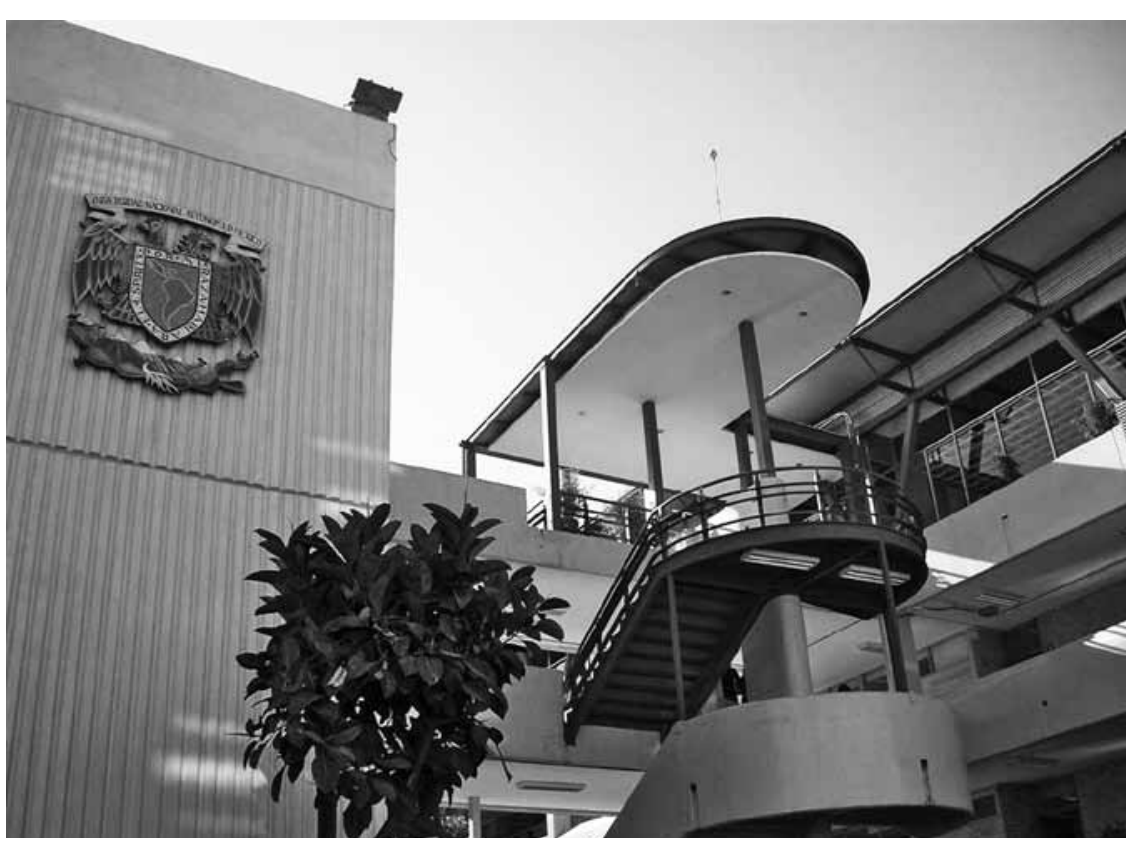

electrónica e impresa a doscientas universidades de todo el mundo.

Por lo que a través de este medio reconocemos el apoyo otorgado por nuestros lectores, autores, revisores y a todo el equipo que integra la "Revista Enfermería Universitaria" por los logros alcanzados ya que esto nos impulsa para asumir los desafíos académicos y sociales de este proyecto editorial de nuestra Escuela y de nuestra Alma Mater. Que hoy en este número se transforma. 


\section{Tú Revista}

Enfermería Universitaria

\section{Se trasforma....}

- Nuevos criterios

- Nueves secciones

- Nueva imagen

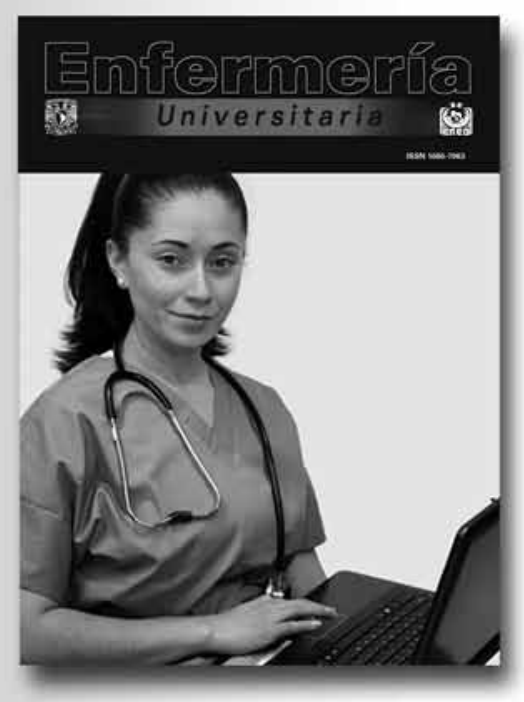

Editorial

Investigación

Artículos de revisión

Innovación para la práctica

Cartas al editor 


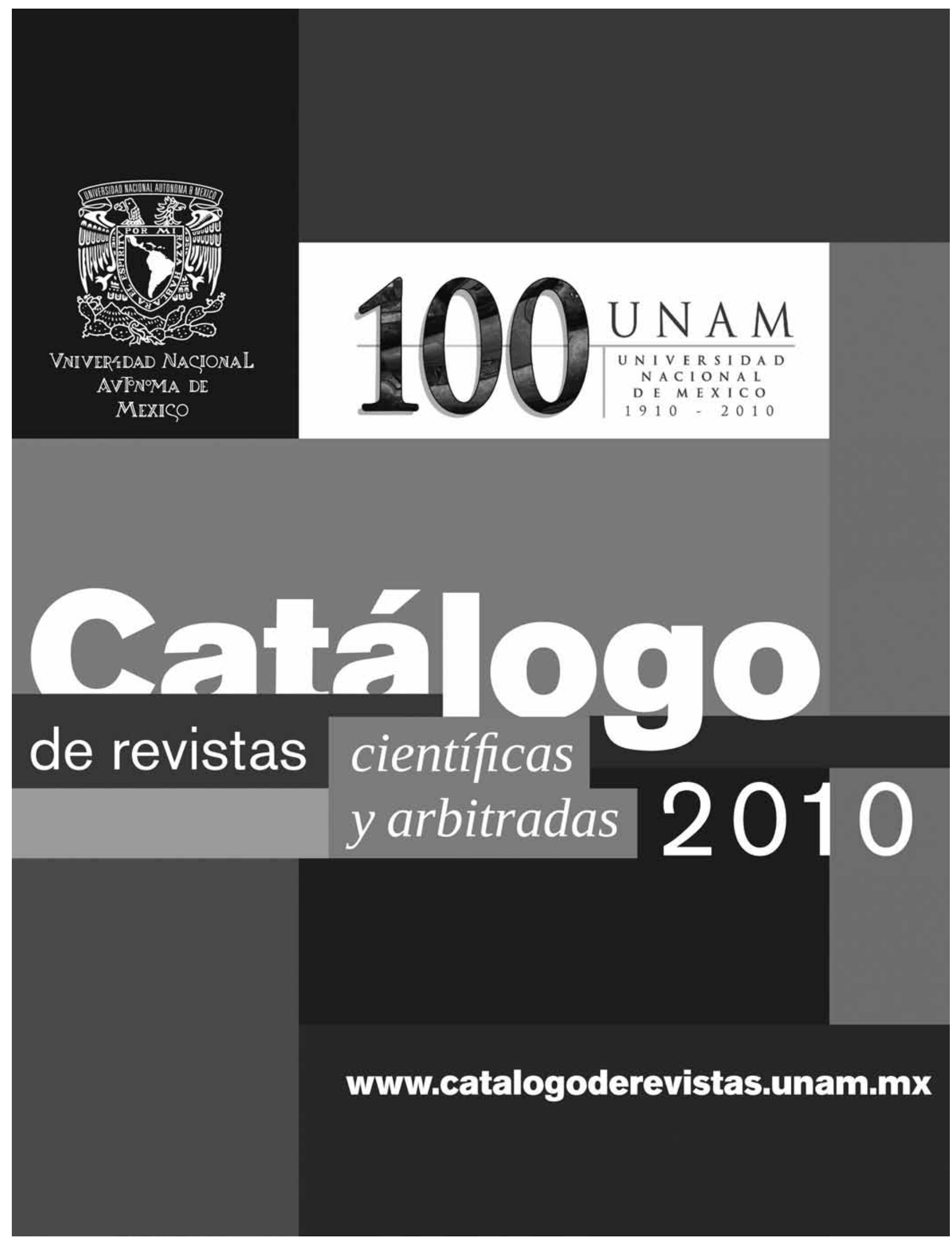




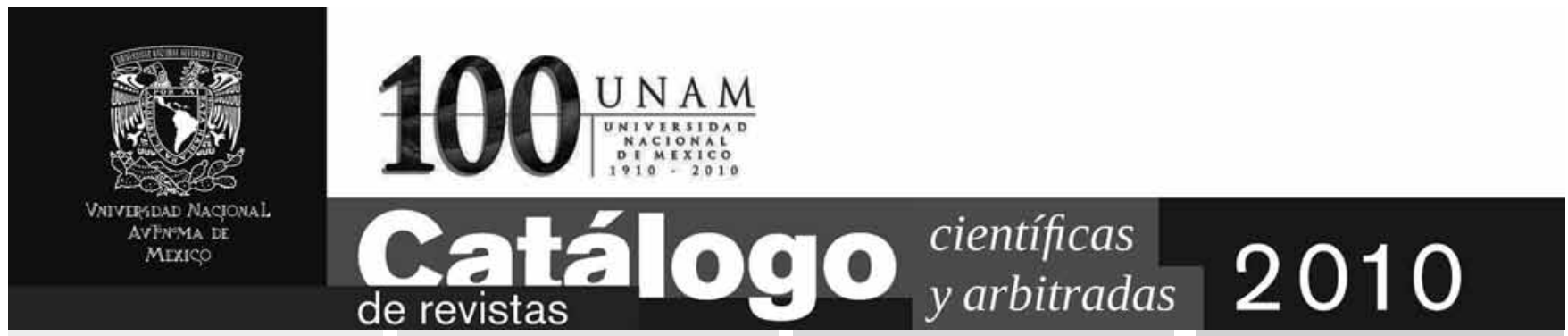

1. Acta Comportamentaria

2. Acta Poética

3. Acta Sociológica

4. Advances in Applied Clifford Algebras

5. Anales de Antropología

6. Anales del Instituto de Investigaciones Estéticas

7. Antropología Física Latinoamericana

8. Anuario de Filosofía

9. Anuario de Historia

10. Anuario de Letras

11. Anuario de Letras Hispánicas

12. Anuario de Letras Modernas

13. Anuario de Literatura Dramática y Teatro

14. Anuario del Colegio de Estudios Latinoamericanos

15. Anuario Mexicano de Derecho Internacional

16. Anuario Mexicano de Historia del Derecho

17. Archipiélago. Revista Cultural de Nuestra América

18. Atención Familiar

19. Atmósfera

20. Biblioteca Universitaria

21. BIOCYT. Revista Electrónica

22. Bitácora Arquitectura

23. Boletín de la Sociedad Geológica Mexicana

24. Boletín del Instituto de Investigaciones Bibliográficas

25. Boletín Mexicano de Derecho Comparado

26. Boletín SUAyED

27. Ciencias

28. Contaduría y Administración

29. Critica Jurídica

30. Crítica. Revista Hispanoamericana

31. Crónicas

32. Cuadernos Americanos
33. Cuestiones

Constitucionales.

Revista Mexicana de

Derecho Constitucional

34. Cultura y Representaciones Sociales. Un Espacio para el Diálogo Transdisciplinario.

35. Derecho Comparado de la Información. Comparative Media Law Journal

36. Diálogo Jurisprudencial

37. Diánoia

38. Dimensión Económica

39. Economía UNAM

40. Educación Química

41. Encrucijada. Boletín del Seminario de Escultura

42. Enfermería Universitaria

43. Estudios de Antropología Biológica

44. Estudios de Cultura Maya

45. Estudios de Cultura Náhuatl

46. Estudios de Historia Moderna y Contemporánea de México

47. Estudios de Historia Novohispana

48. Estudios Latinoamericanos

49. Estudios Políticos

50. Eutopía

51. Geofísica Internacional

52. Ingeniería, Investigación y Tecnología

53. Investigación Bibliotecológica

54. Investigación Económica

55. Investigaciones Geográficas.

56. Journal of Applied Researchand Technology

57. Journal of Behavior, Health \& Social Issues. Revista de Conducta, Salud y Asuntos Sociales
58. La Experiencia Literaria

59. Latinoamérica. Revista de Estudios Latinoamericanos

60. Literatura Mexicana. Centro de Estudios Literarios

61. Medievalia

62. Mensaje Bioquímico

63. Mexican Law Review

64. Mexican Studies

65. Multidisciplina

66. Mundo Nano. Revista Interdisciplinaria en Nanociencia y Nanotecnología

67. Norteamérica

68. Nova Tellus. Anuario del Centro de Estudios Clásicos

69. Ola Financiera

70. Península

71. Perfiles Educativos

72. Perspectiva Interdisciplinaria de Música

73. Poligrafías Revista de Literaturacomparada

74. Problema. Anuario de Filosofía y Teoríadel Derecho

75. Problemas del Desarrollo. Revista Latinoamericana de Economía

76. Prolija Memoria. Estudios de CulturaVirreinal

77. Psicología y Ciencia Social

78. Reforma Judicial. Revista Mexicana deJusticia

79. Revista Jurídica Amicus Curiae

80. Revista Aidis

81. Revista de Derecho Privado. Nueva Serie

82. Revista de la Facultad de Derecho deMéxico

83. Revista de la Facultad de Medicina

84. Revista de Literaturas Populares
85. Revista de Relaciones Internacionales de la UNAM

86. Revista de Zoología

87. Revista Electrónica de Psicología delztacala

88. Revista Internacional de Ciencias Sociales y Humanidades SOCIOTAM

89. Revista Internacional de Contaminación Ambiental

90. Revista Latinoamericana de Derecho Social

91. Revista Latinoamericana de MedicinaConductual

92. Revista Mexicana de Análisis de la Conducta

93. Revista Mexicana de Astronomía y Astrofísica

94. Revista Mexicana de Biodiversidad

95. Revista Mexicana de Ciencias Geológicas

96. Revista Mexicana de Ciencias Políticas y Sociales

97. Revista Mexicana de Opinión Pública

98. Revista Mexicana de Sociología

99. Revista Odontológica Mexicana

100. Revista Pueblos y Fronteras

101. Theoría. Revista del Colegio de Filosofía

102. Tip. Revista

Especializada en Ciencias Químico Biológicas

103. Tlalocan

104. Trabajo Social

105. Vertientes

106. Veterinaria México 